\title{
ОГЛЯД ОКРЕМИХ МАТЕМАТИЧНИХ МЕТОДІВ ТА АЛГОРИТМІВ ОПРАЦЮВАННЯ МЕДИЧНИХ ЗОБРАЖЕНЬ НА ПРИКЛАДІ ТЕХНОЛОГІЇ ВОЛЬФРАМ МАТЕМАТИКА (MEDICAL IMAGE PROCESSING)
}

О. Є. Прокопченко

\author{
Запорізький державний медичний університет
}

\begin{abstract}
Проаналізовано основні методи та алгоритми математичної обробки медичного зображення як об'єкта комп'ютерної математики. Представлені методи та алгоритми системи комп'ютерної математики є актуальними і можуть знайти застосування в галузі обробки медичних зображень - автоматизації процесу обробки зображень; в якості інструменту вимірювання та визначення оптичних параметрів; ідентифікації і формування бази медичних зображень. Впровадження представлених окремих методів та алгоритмів комп'ютерної Вольфрам Математики сприяє оптимізації процесу опрацювання і представлення медичних зображень.
\end{abstract}

Ключові слова: медичне зображення, математичні методи та алгоритми, комп'ютерна математика.

\section{ОБЗОР ОТДЕЛЬНЫХ МАТЕМАТИЧЕСКИХ МЕТОДОВ И АЛГОРИТМОВ ОБРАБОТКИ МЕДИЦИНСКИХ ИЗОБРАЖЕНИЙ НА ПРИМЕРЕ ТЕХНОЛОГИИ ВОЛЬФРАМ МАТЕМАТИКА (MEDICAL IMAGE PROCESSING)}

А. Е. Прокопченко

\section{Запорожский государственный медицинский университет}

\begin{abstract}
Проанализированы основные методы и алгоритмы математической обработки медицинского изображения как объекта компьютерной математики. Представленные методы и алгоритмы системы компьютерной математики актуальны и могут найти применение в области обработки медицинских изображений - автоматизации процесса обработки изображений; в качестве инструмента измерения и определения оптических параметров; идентификации и формирования базы медицинских изображений.

Представленная в статье проблема актуальна также для системы современного медицинского обучения. В качестве примера использования Вольфрам Математики могут быть рассмотрены соответствующие демонстрации, например, специальной обработки рентгенограмм и морфологических изображений. Данные методы служат для повышения диагностической значимости и ценности медицинского (клинического) исследования и могут служить в роли учебной интерактивной демонстрации.

Внедрение представленных отдельных методов и алгоритмов компьютерной Вольфрам Математики способствует, в целом, оптимизации процесса практической обработки и представления медицинских изображений.
\end{abstract}

Ключевые слова: медицинское изображение, математические методы и алгоритмы, компьютерная математи-

\section{REVIEW OF MATHEMATICAL METHODS AND ALGORITHMS OF MEDICAL IMAGE PROCESSING ON THE EXAMPLE OF TECHNOLOGY OF MEDICAL IMAGE PROCESSING FROM WOLFRAM MATHEMATICA}

O. E. Prokopchenko

\section{Zaporizhzhya State Medical University}

The article analyzes the basic methods and algorithms of mathematical processing of medical images as objects of computer mathematics. The presented methods and computer algorithms of mathematics relevant and may find application in the field of medical imaging - automated processing of images; as a tool for measurement and determination the optical parameters; identification and formation of medical images database.

Methods and computer algorithms presented in the article \& based on Wolfram Mathematica are also relevant to the problem of modern medical education. As an example of Wolfram Mathematica may be considered appropriate demonstration, such as recognition of special radiographs and morphological imaging. These methods are used to

$<$ V O. Є. Прокопченко 
improve the diagnostic significance and value of medical (clinical) research and can serve as an educational interactive demonstration.

Implementation submitted individual methods and algorithms of computer Wolfram Mathematics contributes, in general, the optimization process of practical processing and presentation of medical images.

Key words: medical image processing, mathematical methods and algorithms, computer mathematics.

Вступ. Відомо, що в основі комп'ютерних програмних засобів отримання, збереження, класифікації, обробки експериментальних результатів лежать математичні методи та алгоритми. I незалежно від об'єкта дослідження, результат безпосередньо пов'язаний із всебічним математичним і статистичним аналізом отриманих експериментальних даних $[1,2]$.

Мета роботи: теоретичне обгрунтування значення та можливостей впровадження додаткових методів комп'ютерної математики в процес опрацювання результатів експериментальних досліджень, представлених у формі медичних зображень для отримання додаткової інформації.

Основна частина. Виконано огляд та аналіз науково-прикладних джерел щодо застосування окремих математичних методів та алгоритмів комп'ютерної обробки медичних зображень.

Медичне зображення являє собою сучасну форму фіксації, збереження і представлення експериментальних даних $[1,3]$. Оцінювання зображення може здійснюватися як завдяки візуалізації, так і за допомогою кількісних аналітичних, математичних, статистичних методів та алгоритмів.

Медичне зображення містить, як правило, комплексну інформацію відносно об'єкта медико-біологічного або клінічного, в тому числі, гістохімічного і патофізіологічного, дослідження. Враховуючи також, що медичне зображення містить значну, і навіть надлишкову кількість інформації, актуальною залишається проблема застосування окремих математичних методів іiі вилучення, представлення та розпізнавання.

Актуальною є проблема розпізнавання окремих структурних елементів на зображенні, визначення їх кількості, форми, розміру, розподілу та, власне, проблема автоматизації процесу опрацювання медичного зображення комп'ютерними (програмними) засобами. Актуальною залишається проблема поліпшення якості медичного зображення - корегування контрастності, інтенсивності, видалення шуму, дефектів і тому подібне.

Аналіз медичного зображення має на меті розв'язання проблеми реєстрації, інтерпретації і класифікації зображень [4, 5]. Актуальною є саме проблема інтерпретації, яка має бути пов'язаною із загальною базою знань або базою медико-біологічних зображень та 3 методами отримання клінічних даних. Прийнято вважати, що аналіз медичних зображень розв'язує наступні проблеми [2]:

- реєстрація та класифікація зображень;

- візуалізація та представлення зображень.

До методів отримання клінічних медичних зображень належать: ультразвукове дослідження, методи мікроскопії, цифрова радіологія, комп'ютерна томографія, методи ядерного магнітного резонансу, позитронна емісійна томографія та інші. Вказані методи належать до загальновизнаних стандартних методів сучасної медичної фізики, що частково розглядаються також в якості складової частини навчальної програми 3 дисципліни «Медична фізика та біофізика», яка належить до так званих «болонських дисциплін» і вивчається в медичних університетах.

Інша сторона актуальності проблеми, що розглядається в даній публікації, пов'язана із вузькою спеціалізацією існуючих програмно-апаратних комплексів, які застосовуються в клінічній та експериментальній практиці, наприклад, медичний комп'ютеризований комплекс аналізу зображень «Діаморф». Комплекс забезпечує автоматичне введення зображень, виділення об'єктів та їх вимірювання. Спеціалізовані програмні засоби розглядаються виробниками в якості невід'ємної частини апаратних засобів дослідження, що робить неможливим відокремлене їх використання.

Тому актуальним залишається використання саме окремих, але універсальних математичних методів та алгоритмів дослідження медичних зображень. До останніх можна віднести систему комп'ютерної математики від компанії Вольфрам (Wolfram Mathematica) (поточна версія 10), що позиціонується виробником як універсальний математичний засіб або обчислювальне хмарне середовище із відповідною мовою програмування (Wolfram Natural Language Understanding System), системою моделювання (SystemModeler), підтримкою хмарних технологій (Wolfram Cloud), системою розгортання рішень стосовно наукових досліджень (Wolfram Universal Deployment System та Wolfram Discovery Platform). Крім того, Mathematica містить формат обчислюваль- 
них документів, що зберігає інтерактивність та динамічність. Останнє є актуальним для вирішення навчально-методичних проблем.

Засоби комп'ютерної математики, такі як Wolfram Mathematica постійно вдосконалюються, в тому числі, за рахунок розвитку технології опрацювання зображень (Image Processing). Система комп'ютерної математики містить також так звані готові рішення, наприклад, модуль опрацювання медичних зображень (Medical Image Processing) [6].

Вибір технології розв'язання проблеми може базуватися на готових демонстраційних рішеннях (на момент написання статті приблизно десять тисяч математичних прикладних демонстрацій з відкритим кодом міститься за адресою розробника demonstrations.wolfram.com). Обробка або опрацювання медичного зображення програмними засобами від Вольфрам Математика (Medical Image Processing), як правило, використовуються $з$ метою поліпшення якості зображення, компенсації дефектів, що є наслідком використання певної апаратної або вимірювальної системи, і розпочинається 3 поліпшення видимості та відбору, наприклад, окремих анатомічних чи гістологічних структур; сегментації, тобто виділення межі між структурними компонентами зображення; виявлення і розрахунку

\section{Література}

1. Birkfellner W. Applied Medical Image Processing, Second Edition: A Basic Course / W. Birkfellner. - CRC Press Textbook, 2014.-455 p.

2. Petrou M. Image processing: The Fundamentals / M. Petrou, C. Petrou. - Publisher : Wiley, 2010. - 818 p.

3. Parker J. R. Algorithms for Image Processing and Computer Vision Paperback / J. R. Parker - Publisher : Wiley, 2010. — $504 \mathrm{p}$. кількісних параметрів, наприклад, визначення кількості, розрахунку площі, об'єму; розрахунку та аналізу гістограми зображення (кількісний і якісний аналіз зображення); визначення і корегування розподілу рівнів інтенсивності та контрастності; використання методів трансформації зображення, в тому числі забарвлення півтонових зображень та фільтрації ускладнених зображень; покрокового порівняння елементів декількох зображень.

Представлені методи та алгоритми системи комп'ютерної математики є актуальними і можуть знайти застосування в галузі обробки медичних зображень - автоматизації процесу обробки зображень; в якості інструменту вимірювання та визначення оптичних параметрів; ідентифікації і формування бази медичних зображень. Останнє також є актуальним для медичної освіти. Вольфрам Математика може бути використана для спеціальної обробки рентгенограм і морфологічних зображень та може підвищити діагностичну значущість медичного (клінічного) дослідження.

Висновки. Впровадження представлених методів та алгоритмів комп'ютерної математики сприяє оптимізації процесу опрацювання і представлення медичних зображень.

4. Bishop C. M. Pattern Recognition and Machine Learning (Infonnation Science and Statistics) / C. M. Bishop. - Springer, 2007.-738 p.

5. HaarB. M. Romeny front-end vision and multi-scale image analysis: multi-scale computer vision theory and applications, written in Mathematica (Computational Imaging and Vision) / B. M. Haar Romeny. - Springer, 2003. - 466 p.

6. Saquib N. Mathematica data visualization, create and prototype interactive data visualizations using mathematica / N. Saquib. - Publisher : Pack Year, 2014. - 132 p. 